\title{
Theory of Practice as Alternative Pathway for Responsiveness in Engineering Education in Africa.
}

\author{
Dr. Kehdinga George Fomunyam \\ Teaching and Learning Development Center, Mangosuthu University of Technology, Durban, South Africa.
}

\begin{abstract}
Engineering education is the job of teaching the engineering skills and principles practical practice. It is also one of African education systems' most important engines and pillars, as well as a key factor in maintaining social growth and development. But despite how important engineering education is for the African continent as a whole, there is still a serious problem in applying practice to most of the things taught to engineering students on the continent. It may be true that nothing is more practical than a good theory but it is important to put a good theory into practice for the growth of engineering education in Africa, but it is never easy. Moreover, in recent times engineering education in Africa remains unresponsive to today's workplace demands imposed on engineering graduates. A number of studies and cross-examinations were conducted with the objective of suggesting effective ways and methods by which African engineering education can be responsive and match other established continents on earth. Despite these efforts of numerous writers, scholars and researchers in the field of critical engineering education in Africa, much remains to be desired, as on the continent education in engineering remains largely unresponsive to the realities of today. Thus, this study suggests and explores that practice theory can be used as an alternative path to achieving responsiveness in African engineering education. Ultimately, the study concludes that the interweaving of theory with practice becomes much closer to achieving responsiveness than the norm for engineering education in Africa. This can be accomplished by offering class lessons, tutorials, assignments, and exams that are more genuine, realistic, and practical, i.e., resembling more real-life issues, and that background should in most cases be aligned with real-life situations.
\end{abstract}

Keywords: Engineering Education, Africa, Responsiveness, Theory of Practice, Engineering.

\section{INTRODUCTION}

Engineering education is a four-year development based on teaching techniques like maths, software, and engineering concepts. Engineering education is one of the most important engines and pillars of any educational system in any country, and is widely recognized as a leading instrument for fostering social development and growth in Africa.Engineering education deals with educating individuals to become engineers who should be the initiators, facilitators, and implementers of a nation's technical growth. It focuses on teaching methods and the learning process, examines the efficacy of teaching strategies, assesses the appropriateness of engineering curricula, facilities and accreditation programs, as well as industry perspectives in engineering training (Falade, 2016). Therefore, a successful engineering education in Africa is meant to equip students with skills and information that will prepare them for the challenges of the present day, by helping to address social and organizational issues that are eager for engineering. One cannot overemphasize the value of engineering education for the development of the African continent. As Mohamedbhai (2015) rightly argued, there is an urgent need for engineering ability in Africa for several reasons: to accompany its growth trajectory in infrastructure development; to accelerate its industrial development, especially in manufacturing, so that it becomes a net exporter rather than an importer of manufactured goods; to meet its ever-increasing needs in terms of energetics; and finally, for achieving the Millennium Development Goals. This explains in clear terms that African engineering education is essential to the continent's growth, as significant infrastructural growth will occur in the area that is fundamental to human development.

Despite the importance of engineering education in promoting innovations in Africa, the continent's standard of engineering education still leaves much to be desired. In Africa according to Falade, engineering e has witnessed several challenges ranging from poor funding to insufficient facilities both quantitatively and qualitatively at the training institutions, insufficient and outdated equipment, inadequate human resources, conventional pedagogy adoption, brain drain and poor training and retention profiles of workers. Others include weak university/industry collaborations, faulty curricula, poor industrial connection program, unavailability of local codes and testing requirements for training prospective engineers and an insufficient ICT environment, as well as weak linkages between theory and practice. Most African engineering students are bombarded with theoretical details and less practical knowledge, so that they feel confused and discouraged when it comes to putting into practice the theory they learned in school. This explains why most major engineering constructions carried out in African countries are often carried out by foreign construction firms, as multinational engineering firms have a large local presence on the continent, and these foreign firms prefer to import their own skilled labour. This is due to the severe lack of engineering resources on the continent, as a result of the continent's low quality engineering education. All these concerns posed about engineering education in Africa suggest 
that Africa's engineering education curriculum lacks responsiveness to the actual needs of organizations and society as a whole.

In the literature a variety of approaches have been proposed that can be useful in ensuring that engineering education in Africa becomes sensitive in this day and age, but this phenomenon still persists. To this end, this study suggests practice theory as an alternate approach that can be used to overcome this problem, as there is a discrepancy between theory of engineering and practice on the African continent. Practice theory seeks to connect theory with practice and Bourdieu (1972) has as his major contributor.As pointed out earlier, African engineering education students are bombarded with theoretical knowledge and less practical information, and thus the theory of practice can be useful in this respect.

This paper is broken down into parts to achieve the study's objective. The first part was used to address the drawbacks of engineering education in Africa, while the second section of this study clarified $n$ specifics the practice principle and the third part was used to clarify the curriculum responsiveness concept. The fourth part of the paper outlined how Practice Theory can be used to achieve engineering education responsiveness in Africa. The final section of the paper was used to put the analysis to a close.

\section{DRAWBACKS OF ENGINEERING EDUCATION IN AFRICAN UNIVERSITIES}

As of now, engineering education in Africa still faces a number of challenges in providing the industry with talented graduates ready to provide on-the-job services (Electronic Design, 2009). These challenges include a lack of industry participation, ignorance of the teachers, outdated curricula and a weak link between theory and practice, and these have created a gap between the level of training graduates have received against the expectations of employers in the country's sector and industry despite their huge resources (Idris \& Rajuddin, 2012).According to Idris and Rajuddin, the difference between theory and practice in engineering education has led to the lack of cutting-edge technology, low practical know-how and lack of trust among most engineering students in Africa. To this end, most engineering graduates in Africa when employed are engaged by the industries in many retraining to develop their skills because they are considered to be unemployed at the first intake stage. The multi-million dollar question then is how does engineering education succeed in connecting theory with practice in Africa?

African learners have thus since faced the conflicting demands of matching the theoretical essence of engineering education with real world experience (Abah, Mashebe, \& Denuga, 2015). Different scholars have continued to argue that translating what has already been learned into practice is difficult for students in Africa, because it has the potential importance of solving contemporary social and organizational problems. This is because Kaya and Seleti (2014) insisted that mixing theory and practice would increase the importance of engineering education in the local as well as global context. Popp (2018) claims that it is of great importance to combine theoretical knowledge structures with practice, instead of maintaining the conventional approach which prevails. This is because they each have important roles to play in the sciences of teaching and learning.

\section{UNDERSTANDING THE THEORY OF EDUCATIONAL PRACTICES}

Education is not, of course, a theoretical practice, but a realistic practice that deals with the general task of improving the minds of pupils through the teaching and learning processes. However, while it is unlike psychology or sociology in that it does not require the creation of theories and interpretations, schooling is similar to theoretical practices in being a systematic activity that can only be understood through analogy with the sense of thought in terms of knowing what its practitioners are doing and what they are. Anyone engaged in educational pursuits must already have some 'theory' in this context, no less than anyone engaged in theoretical pursuits, by virtue of which his activities are carried out and his achievements measured.

A careful interweaving and sequencing of theoretical and functional elements, according to Schatzki (1997), will help students add elements to those they have already acquired. A long and lasting learning process should take place in engineering education, relating elements of theory and experience in a way that is relevant from the viewpoint of the students and carefully organized so that they can develop meaningful wholesale of expertise, skills and attitudes. In addition, some similar characteristics are shared by the theories that direct theoretical practices and by those that direct instructional practice. For example, both are primarily the result of established and ongoing rituals and, as such, constitute the ways of conceptualizing interactions that are considered ideal for the social contexts in which the respective activities are carried out. Therefore the fact that the driving principle of a theoretical approach can be only learned by a deliberate and systematic introduction to 'methodology' does not change the fact that it is an inherited and agreed way of thought, no less than a philosophy of educational practice. Second, each mode of thinking employs an interrelated collection of ideas, beliefs, theories, and values that enable circumstances and events to be interpreted in ways that are relevant to their specific concerns. For instance, while both psychology and educational practices may be organized around terms such as 'learning,' 'knowledge,' 'interest,' and the like, their meanings can vary with the various conceptual schemes through which their representation takes place.

There are problems for educational practitioners as with theoretical practices when their techniques and procedures are no longer successful. These theory-practice gaps may arise when, for example, the importance of conventional methods of evaluation is no longer apparent, or when any common form of teaching is found to be ineffective in a new situation, and they are typically overcome by practitioners changing their practices in the light of the context of understanding they have already obtained. As with theoretical endeavours, however, the differences can be such that they pose concerns not just about the efficacy of particular practices but also 
about the ability of the entire conceptual context through which these practices are interpreted to provide a satisfactory characterization of educational activities at all. Dissatisfaction with 'traditional' educational methods, for example, led some educators to re-evaluate the basic habits of thinking in terms of making this kind of education intelligible and considered desirable.

\section{CONTRADICTION BETWEEN THEORY AND PRACTICE IN EDUCATION}

When theory and practice are looked at in this way, it becomes increasingly clear that the kind of differences between them that typically trigger concern are not those that exist between a practice and the theory that governs the activity, but rather those the emerge because it is believed the theory of education applies to theories other than those that already govern educational pursuits (Schilb, 1991). For example, the communication gap only exists because the language of educational theory is not the language of educational practice, while the differences between educational theory and its practical implementation may only occur because the practitioners do not perceive or test the theories they are given according to the standards used by those engaged in theoretical pursuits.

Now the problem with this whole definition of educational theory is that it fails to consider the vast theoretical forces already possessed by educational practitioners and thus distorts, in many important respects, the relationship between theory and practice and the manner in which differences between them will exist. Considering theory-practice discrepancies as 'communication' or 'implementation' difficulties that are unique to practical activities such as education, for example, distorts the fact that a discrepancy between theory and practice is the kind of difficulty that can also arise in any theoretical undertaking. Secondly, the belief that these problems can somehow be defined and handled 'in theory' and then 'applied' in practice appears to hide how they are actually produced from practitioners' experience and only arise when it is found that the manner in which these experiences are typically structured is ineffectual. Third, the assumption that the problems created by these differences can be resolved by translating theoretical knowledge into rules of action overlooks the simple point that differences between theory and practice, whether they exist for theorists or educators, are closed by the practitioners themselves formulating decisions in the light of the context of understanding they already possess (Waterman \& Williams, 1995). It therefore overlooks the fact that since only educational practitioners are actually engaged in educational activities, it is the theory that guides their practices, rather than the theory that guides any theoretical practice, that constitutes the basis of their educational principles, decides if and when there are any differences between practice and these principles and guides any decisions and actions.

The differences between theory and practice that everyone deplores are, in reality, intrinsic to the belief that educational theory can be created from theoretical and practical contexts other than the theoretical and practical context to which it is to be implemented (Jansen, 2018). Consequently, because this kind of view is so common, it is hardly surprising that the holes created thereby are interpreted as impediments which can only be eliminated by seeking ways to persuade teachers to embrace and implement the theory they are being provided. However, if it is understood that there is nothing that can be reliably referred to by the term 'educational theory' other than the theory that actually governs educational practices, then it becomes clear that a theoretical operation directly concerned with affecting educational practice can only do so by affecting the theoretical context through which those activities are rendered understandable.

In this view, the theory of education is not a 'applied theory' that 'draws on' theories from philosophy, social science or some other basis of experience, but rather refers to the whole undertaking of critically assessing the adequacy of the concepts, beliefs, assumptions and principles incorporated into the theories of predominant educational practice. This doesn't mean that the relationship between theory and practice is such that theory 'implies' practice, or is 'derived' from practice, or even 'reflects' truth. Theory also changes practice by modifying the ways in which practice is perceived and understood by subjecting to rational scrutiny the principles and justifications of existing and ongoing practical practices. The transformation therefore does not take place from theory to practice as such, but from irrationality to reason, from ignorance and habit to understanding and reflection.

Researchers have stated that prospective students frequently encounter inconsistencies between the theory of education and how it is applied in the real world (Anagnostopoulos, Smith \& Basmadjian, 2007; Carr \& Kemmis, 1986; Postlethwaite \& Haggarty, 2010). Confronted with this question, the prospective student finds experiential experience more important than what they study in universities. The practitioner students have the feeling of disillusionment with the theory of education that is taught at university. Some scholars argue that there are inherent inconsistencies in what the students learn in various environments. Anagnostopoulos et al. (2007), who study student education research, argue that the beliefs, cultures, and methods used in university and school settings differ. Anagnostopoulos et al. (2007) assume the theory and practice still have a tension. These two distinct realms are related via an abstraction and application method. Theory deterritorializes practice to clarify this method by way of theory, and practice reterritorializes theory: a theory that becomes practice; and a practice that becomes theory. To illustrate, abstract practice is theory, and the theory is applied to practice. The best way to get these two camps to speak to each other is to find out what the theory says that brings meaning to the practitioners.

\section{Deconstructing the concept of responsiveness}

Responsiveness in a more general word means performing a program efficiently, effectively, immediately and without delay. So being sensitive means trying to solve a problem quickly. In the literature, responsiveness has always been calculated using four distinct variables which make responsiveness a higher order construct. Economic responsiveness, cultural responsiveness, disciplinary 
responsiveness and pedagogical or learning responsiveness are the four variables used in measuring responsiveness.

Economic responsiveness deals with engineering education's ability to train qualified professionals in various sectors of the economy (Fomunyam \& Teferra, 2017). Fomunyam and Teferra argued that being economically sensitive would not only make students earn degrees, but will also make them very qualified and ready for real-world jobs and build swift workplace solutions. Economic sensitive engineering education can produce students who adapt quickly to economic challenges through innovation, inventiveness and critical thinking. Economic responsiveness attaining engineering education in Africa means that engineering education in Africa should be able to train sufficient numbers of highly qualified and professional engineers in development main sector of the African economy. Consequently, engineering education in Africa should be sensitive to the prevailing labor market by integrating in African engineers needed by a modern and diversified economy the requisite high-level qualifications, expertise and skills.

Thus, in this era, a curriculum is economically sensitive when the curriculum has the potential to churn out graduates who can cope with the digitisation of the organizational work space. This means that in this age of globalization, an economically sensitive curriculum in engineering education would provide students with the skills and know-how to build, develop and cultivate long-lasting solutions to organizational issues. Therefore, an economically sensitive curriculum will generate engineering students who can find solutions not only to current organizational and societal issues but also to future organizational and societal issues.

On the other hand, cultural responsiveness is the capacity of engineering education to teach African students how to embrace and react positively to cultural dissonance at workplace (Moll, 2004). Ladson-Billings (1994) argued that cultural responsiveness acknowledges the value of having cultural references for students included in all areas of learning. Cultural tolerance therefore requires taking into account the student and employee diversity. Gay (2010) noted that where engineering education is culturally sensitive, graduate engineers would have thorough knowledge that there are many different groups inside the workplace, and how to cope with these cultural differences on the workplace effectively. To this end, Villegas and Lucas (2007) argued that culturally sensitive engineering education will instil in the students the habit of embracing a wealth of diversity and cultural strengths which help to achieve organizational and societal goals.

Because of the benefits of diversity, most companies and communities are embracing cultural diversity and therefore have workers from different backgrounds. Engineers who have no grounded knowledge of how to cope in a diverse organizational setting may find it difficult to function efficiently, thereby affecting overall productivity and performance in the organization and in society. That's why being culturally sensitive to engineering education can be useful in solving engineering issues that affect African organizations and societies. Where engineers are comfortable collaborating with other workers from different backgrounds and religious backgrounds, companies can easily set up a diverse community to provide solutions to challenges from various perspectives, thereby helping organizations and African communities achieve their engineering goals.

Furthermore, disciplinary responsivity is the capacity of engineering education to be up-to - date with existing field research as well as to encourage new developments within the discipline (Ferdinand, 2009). Therefore, to be disciplinary sensitive in engineering education in Africa, it needs to be proactive and respond quickly to new developments in the engineering sector. Engineering education is always changing with new technologies and methods of carrying out projects, and therefore it is necessary to structure engineering education in Africa in such a way that African engineers can cope with any new challenges and innovations in this area. Fomunyam and Teferra (2017) argued that in order to be disciplinary sensitive to engineering education, it must be up-to - date with regard to field research and also organized in ways that are relevant to everyday life, particularly because information is largely for application. Africa's disciplinary responsive engineering education will ensure that its curriculum covers recent developments in the engineering world, and will also encourage students to think globally to ensure organizational success. Engineering organizations are required to face new challenges as time goes by, so it is vital that African engineering education is supervised by inculcating findings from new research into lessons given to students, as this will allow students to address any new challenges they may face in their workplace.

Finally, the capacity of engineering education to respond to the individual needs of the students is pedagogical or learning responsiveness. Fomunyam and Teferra (2017) thought that there are often different students in each classroom with different needs and abilities about teaching and learning. Thus, engineering education should be organized in such a way that it will adapt to individual learners ' needs, without which learning could not take place. Therefore, in order to be relevant to engineering education in Africa, the curriculum needs to adapt to the needs of engineering students in the curriculum by then teaching in terms that are open to them and evaluating them in ways they understand. But there is no proof that Africa's engineering education is learning responsively. This is because engineering students are expected to adapt to the business education classes in most situations, rather than the other way round. This may be the reason why students in engineering education do not learn enough in class as they may be disinterested with activities taking place in class. Ultimately, graduating disinterested students in class can lead to less skilled engineers who do not know how well to function when faced with workplace engineering problems. This might make the African society unable to achieve its goals when it comes to solving the continent's engineering problems.

In summary, the curriculum has to become economically sensitive, disciplinary sensitive, culturally responsive and responsive to learning in order to achieve maximum responsiveness in engineering education in Africa. But engineering education in Africa is believed not to be receptive 
International Journal of Engineering Research and Technology. ISSN 0974-3154, Volume 13, Number 9 (2020), pp. 2491-2497

(C) International Research Publication House. https://dx.doi.org/10.37624/IJERT/13.9.2020.2491-2497

to the changing demands of today's societies. Africa continues to be plagued by weak infrastructure, such as weak road networks, poor rail lines and a large housing shortage. Foreign engineering organizations such as Julius Berger, Setraco and Arab Contractors are often hired by governments in Africa to conduct major construction projects in Africa. This clearly shows a big problem with the need for and the urgent response to the African engineering education. To that end, this study proposes practice theory as a possible way to make the engineering education of Africa responsive to developments recorded elsewhere in the world.

\section{Conceptualizing theory of Practice as an Alternative Pathway for Responsiveness in Engineering Education in Africa}

It may be true that nothing is more realistic than a good idea but it is never easy to bring a good theory into practice. A first promising approach to this problem as proposed by the theory of practice is to interweave theory and practice far closer than before by providing more realistic tasks, i.e., more like reallife issues, and the meaning of engineering concepts should be connected to real-life circumstances (Pilot \& Bulte, 2006). Authenticity in assignments provides students with a concrete background, enhances motivation, creates need-to-know and encourages the creation of skills in functional societies. As stated by Vincenti (1990) for engineering, bridging the gap between the two typically requires considerable effort. Likewise, during their realistic engineering assignments many engineering students fail to leverage theoretical perspectives (Dym, Agogino, Eris, Frey \& Leifer, 2005). In particular, it turns out to be difficult for students to apply engineering theory and all too often they struggle to make the relation between theory and practice in this important area. One way for engineering students in Africa to interweave theory and practice is to have more hands-on experience in laboratories doing industry-relevant practical work that is, putting into practice what is learned in the classroom. In order to do this, engineering students need to have in-depth knowledge of practical laboratories, accessible laboratory spaces, quality laboratory resources, and available engineering gear. Furthermore, it may be important to interweave theory and practice, establish business collaborations, gain more grant funding, build multidisciplinary laboratory spaces and/or scour the world of engineering laboratory equipment for the best manufacturer. Moreover, in a more realistic problemsolving setting, the engineering education curriculum in Africa must be structures in a way that allows students to understand and synthesise knowledge.

Consequently, a careful interweaving and sequencing of theoretical and functional elements may help students build elements to those they have already acquired. A long and lasting learning process should take place in engineering education in Africa, relating elements of theory and experience in a way that is relevant from the viewpoint of the students and carefully designed so that they can develop meaningful wholesale knowledge, skills and attitudes. In other words, engineering concept should focus on a chain of actions and motivations, motivating and directing students to do something concrete and practical with the theory provided and enriching their understanding by focusing on their experiences in synthesizing actions with theory in practice through credible assignments and performing activities.

Another preferred way of connecting theory to practice in engineering education is by using case studies. Empirical studies have shown that case-based or case-method teaching is an efficient pedagogical technique in areas such as business, education, law, medicine, engineering, and e-learning (Angeli, 2004). This approach will help present some aspect of the real-life scenarios to students by implementing and incorporating expertise, skills, theories and experience (Ching, 2014).Case study should be made an important pedagogy in the training of engineering students in Africa, as the promotion of analytical and realistic thinking has been established. It can equip African engineering students with the necessary and realistic skills that they need to succeed in the workplace by giving them examples of real-life scenarios. A case has a plot or tale that describes a series of events that occur in a given place over time (Shulman, 1992), and has essential features that are useful for learning. According to Ching, narrative types of cases require the attention of students, easily retain in the memory and catch their interest and devotion. As a consequence, cases can be stimulating and enriching, and can promote higher-order thought such as logical and analytical thought, problem solving, and decisionmaking. It is therefore recommended that case studies be implemented as part of Africa's engineering education learning program, as it has the potential to teach students realistic and complex engineering situations and also making engineering education in Africa responsive

\section{CONCLUSION}

There is a clear indication that there is a significant challenge in applying engineering practice and students often frequently struggle to link theory and practice in Africa, and hence lack responsiveness. It was observed that the theoretical aspect of engineering education in Africa has not always kept pace with evolving demands from employers as countries are heading towards more market-oriented economies, making it difficult for African countries to bridge the gap between theory and reality with respect to engineering education. This paper ends with some key points to that end.

First, it is very important to allow engineering students in Africa to explore important theoretical concepts through practical assignments (experiments, excursions, product analysis, etc.). It is important to concentrate on practice in such a chain of activities that is directly applicable to the engineering problems that are on offer. To this effect, engineering education curriculum in Africa should be configured in a manner it ensures the right sort and amount of theory, plus adequate space for its implementation in authentic tasks.

In addition, African universities should provide for a sound, long-lasting and sensitive curriculum to make it responsive by making meaningful changes to the current curriculum used in the continent. Changes in curriculums require extensive and expensive planning time, primarily due to the need for near and intense coordination and collaboration, and the need to 
produce unique course materials to achieve needed responsiveness. In the real sense of engineering education, it is very critical for universities in Africa to pursue expert assistance in creating accurate student evaluations where possible. Appropriate teacher training needs to be provided by universities in Africa to engineering tutors in the continent, particularly on practical teaching and evaluation. It can be very useful to have engineering tutors undergo comprehensive training on engineering design and educational theories which lead to accurate evaluation and evaluation practices.

Instructors need to develop their courses in a manner that requires students to understand and synthesize information in a more practical problem-solving environment. There are many educators with the practical knowledge to show students how to solve problems. It requires dedication and selfconfidence to stand in front of a class and admit that they are walking through a problem with the class for the first time or that the problem they are solving has not exactly been solved before. Our education system needs to seek out the instructors who understand how to set up the problems and are willing to admit that they are walking into uncharted territory. It is only then that we will have engineers graduating with practical knowledge that will empower them to design a test, simulation, troubleshooting, or system analysis plan in a manner that will enable them to fully take advantage of each of the tools they learned over the life of their education.

\section{REFERENCES}

Abah, J., Mashebe, P., \&Denuga, D. (2015). Prospect of Integrating African Indigenous Knowledge Systems into the Teaching of Sciences in Africa. American Journal of Educational Research, 3, 668-673.

Anagnostopoulos, D., Smith, E., \&Basmadjian, K. (2007). Bridging the university-school divide: Horizontal expertise and the "two worlds pitfall." Journal of Teacher Education, 58(2), 138-152.

Angeli, C. (2004). The effects of case-based learning on early childhood pre-service teachers' beliefs about the pedagogical uses of ICT. Journal of Educational Media, 29(2), 139-151.

Bourdieu, Pierre (1972). Outline of a Theory of Practice. Cambridge: Cambridge University Press.

Carr, W., \&Kemmis, S. (1986). Becoming critical: Education, knowledge and action research. London: Falmer.

Ching, C. P. (2014). Linking Theory to Practice: A Casebased Approach in Teacher Education. Procedia Social and Behavioral Sciences, 123, 280-288.

Dym, C. L., Agogino, A. M., Eris, O., Frey, D. D., \&Leifer, L. J. (2005). Engineering design thinking, teaching and learning. Journal of Engineering Education, 103120.

Electronic Design (2009). What's wrong with engineering education? Retrieved from https://www.electronicdesign.com/technologies/com munications/article/21767906/whats-wrong-withengineering-education Accessed on 11/09/2020

Falade, F. (2016). Advancement of Engineering Education in Africa: AEEA Perspective. Retrieved from http://www.ifees.net/dvancement-of-engineeringeducation-in-africa-aeea-perspective/ Accessed on $11 / 09 / 2020$

Ferdinand, D.S. (2009). Workforce education and development curriculum responsiveness to culturally and internationally diverse graduate students: A mixed methods study. Carbondale: Carbondale Southern Illinois University.

Fomunyam, K. G., \&Teferra, D. (2017). Curriculum responsiveness within the context of decolonisation in South African higher education. Perspectives in Education, 35(2), 196-207.

Gay, G. (2010). Culturally responsive teaching: Theory, research, and practice. New York: Teachers College Press.

Idris, A \&Rajuddin, M. (2012). The trend of engineering education in Nigerian tertiary institutions of learning towards achieving technological development. International Conference on Teaching and Learning in Higher Education (ICTLHE 2012) in conjunction with RCEE \& RHED.

Jansen, E. (2018). Bridging the gap between theory and practice in management accounting: Reviewing the literature to shape interventions. Accounting, Auditing \& Accountability Journal, 31(5), 14861509.

Kaya, H., \&Seleti, Y.N. (2014). African indigenous knowledge systems and relevance of higher education in South Africa. The International Education Journal: Comparative Perspectives, 12, $30-44$.

Ladson-Billings, G., (1995). But that's just good teaching! The case for culturally relevant pedagogy. Theory into Practice, 34(3), 159-165.

Mohamedbhai, G. (2015). Improving Engineering Education in Sub-Saharan Africa. International Higher Education, Spring, 25-27.

Moll, I. (2004). Curriculum responsiveness: The anatomy of a concept. In H. Griesel (Ed.). Curriculum responsiveness: Case studies in higher education (pp. 1-19). Pretoria: South African Universities ViceChancellors Association.

Pilot, A., \&Bulte, A. M. W. (2006). The use of 'contexts' as a challenge for the chemistry curriculum: Its successes $\&$ the need for further development and understanding. International Journal of Science Education,28(9), 1087-1112.

Popp, C. (2018). Constructivist and sociocultural perspectives on mathematical development. Educational researcher,23(7), 13-20. 
International Journal of Engineering Research and Technology. ISSN 0974-3154, Volume 13, Number 9 (2020), pp. 2491-2497

(C) International Research Publication House. https://dx.doi.org/10.37624/IJERT/13.9.2020.2491-2497

Postlethwaite, K., \& Haggarty, S. (2010). Creativity in design engineering and the role of knowledge: Modelling the expert. International Journal of Technology and Design Education, 15(3), 217-236.

Schilb, J. (1991). What's at Stake in the Conflict between "Theory" and "Practice" in Composition? Rhetoric Review, 10(1), 91-97.

Shulman, J.H. (1992). Case methods in teacher education. NY: Teachers College Press.

Villegas, A. M., \& Lucas, T. (2007). The culturally responsive teacher. Educational Leadership, 64(6), 28-33.

Vincenti, W. G. (1990). What engineers know and how they know it: Analytical studies from aeronautical history. Baltimore, MA, USA: John Hopkins University Press.

Waterman, H. \& Williams, A. (1995). Parallels and contradictions in the theory and practice of action research and nursing. Journal of Advanced Nursing, 22(4), 779-784. 